\title{
MS/MS-libraries with triple quadrupole-tandem mass spectrometers for drug identification and drug screening
}

\author{
W. Weinmann ${ }^{1 *}$, M. Gergov ${ }^{2}$ and M. Goerner ${ }^{1}$ \\ ${ }^{1}$ Institute of Forensic Medicine, University Hospital of the Albert-Ludwigs-University Freiburg, Albertstr. 9, D-79104 Freiburg, Germany \\ ${ }^{2}$ Department of Forensic Medicine, University of Helsinki, P.O. Box 40, FIN-00014 University of Helsinki, Finland \\ * Corresponding author: weinmann@ sun11.ukl.uni-freiburg.de
}

Two MS/MS libraries of drugs created by electrospray ionisation (ESI) and collision-induced dissociation (CID) of the quasimolecular ions have been developed with triple-quadrupole ionspray mass spectrometers. For both libraries three and four different collision energies were used, respectively, to obtain a variety of CID spectra, which were all included separately into the MS/MS libraries. The MS/MS product ion spectra of more than $\mathbf{4 0 0}$ drugs were acquired in positive or negative mode in two laboratories independently. Recently, one of these MS/MS libraries was applied successfully for the identification of drug metabolites and the other has been used for qualitative analysis of drugs in urine samples with data dependent experiments (DDE). In this work, the reproducibility of CID spectra has been tested with three instruments (including two different instruments) in three laboratories. For comparison of CID-spectra, library searching with a combination of the two libraries was performed and fit values were compared. With regard to library fit values CID-spectra were found to be highly reproducible between the instruments, when similar CID gas pressure and collision energy were applied. In addition, the long-time reproducibility of CID over $\mathbf{3 0}$ months with the API 365 was demonstrated. Furthermore, comparisons of in-source CID and CID by MS/MS was given. It can be concluded, that both MS/MS libraries created with APIs 365 can be used with both types of triple-quadrupole instruments from Sciex (API 365 and 2000) for drug identification. Two applications of these MS/MS spectra libraries in combination with data dependent experiments are summarised. 


\section{Introduction}

Besides mass spectra libraries of drugs, pesticides and explosives created by means of electrospray-ionisation or APCI with "in-source" CID - which have been developed by Weinmann [1], Schreiber [2,3] and Marquet [4] - CID in the collision cell of a triple-quadrupole mass spectrometer is more commonly used for structural identification, confirmation and quantitation of drugs in pharmaceutical, environmental, clinical and forensic toxicology [5,6,7]. In many cases in-source CID with different CID-energy levels might be sufficient for drug identification by library spectra [8]. However, if metabolites - which have not been added to insource CID libraries, or unknowns are concerned, MS/MS can be used for structural identification of a compound extracted from body liquids or organs. MS/MS libraries with CID-spectra of the quasimolecular ions can be very useful for this purpose. Therefore, MS/MS libraries of drugs have been developed using triple-quadrupole instruments $[9,10]$. Besides these MS/MS libraries, a procedure using MS/MS and $\mathrm{MS}^{3}$ spectra libraries with ion-trap detectors using wideband excitation has been developed for general-unknown screening [11-14], including the use of data dependent experiments (DDE). DDE involves acquiring a set of survey data, processing it to determine the ions of interest (candidates) and performing a dependent scan (product ion, MRM, precursor ion or neutral loss) on these candidates in the same LC-run ("on-the flight"). DDE has been successfully applied with ion-trap detectors for drug detection with library searching [12-14], as well as with triple-quadrupole mass spectrometers [15,16] and TOF instruments [17].

The reproducibility of CID-spectra obtained with similar or different instruments is of major interest, when working with mass spectra libraries. A comparison of CID spectra obtained with ion-trap and triple-quadrupole mass spectrometers has only been made for peptides - with sufficient comparability of fit values [18]; however, the intra-laboratory comparability of CID spectra of drugs has not been investigated, yet. We here present a comparison of two MS/MS libraries of drugs generated with triple-quadrupole mass spectrometers of the same instrument type in two laboratories with a conventional collision cell (Sciex API 365) and give a comparison with CID-spectra acquired with a triple-quadupole instrument with a linear accelerator collision cell (Sciex API 2000) in a third laboratory.

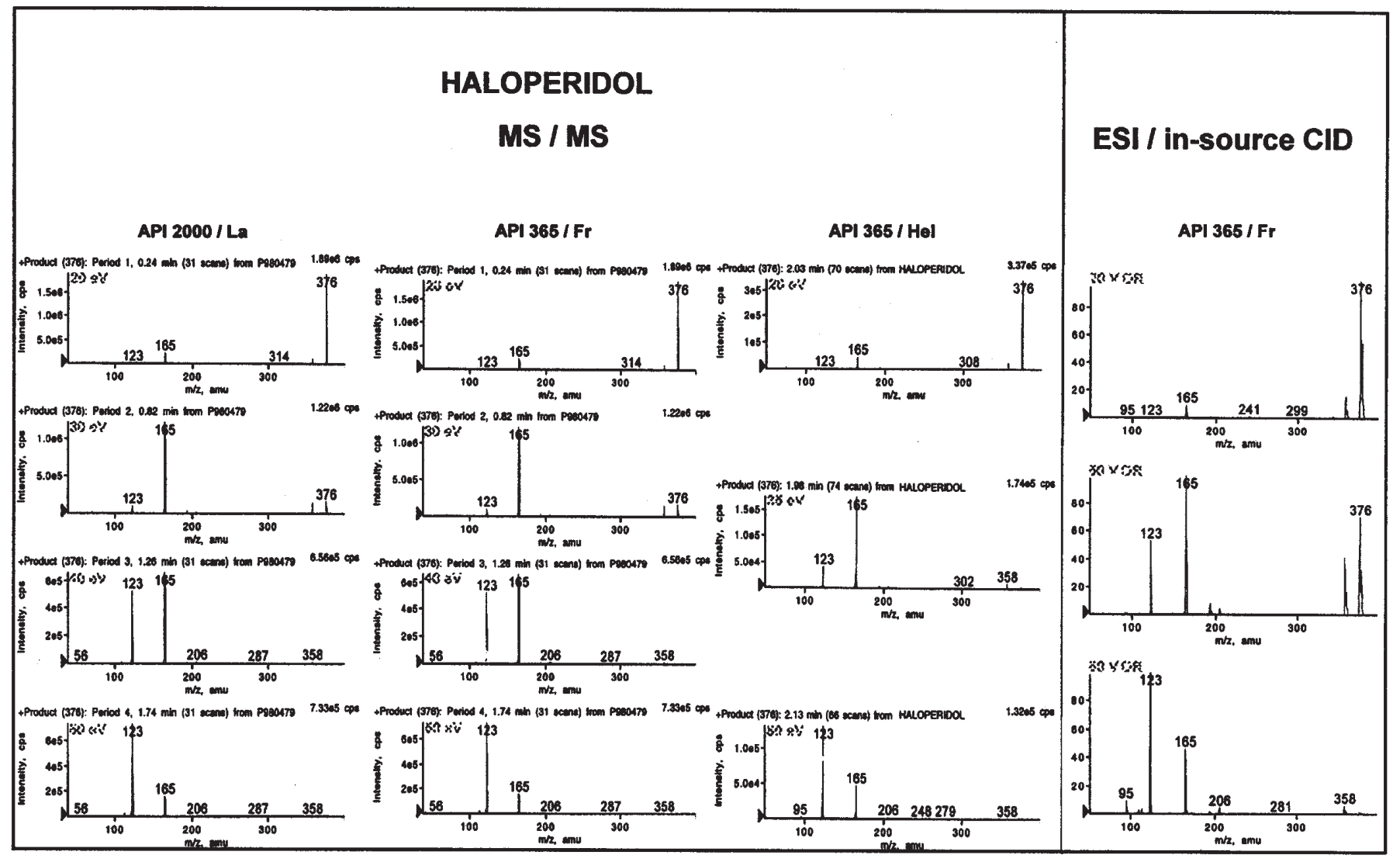

Figure 1. Left panel: MS/MS product ion spectra of haloperidol $\left(\mathrm{M}_{+} \mathrm{H}^{+}, \mathrm{m} / \mathbf{z} 376\right)$ obtained with an API 2000 in Langen (left), API 365 in Freiburg (middle) and API 365 in Helsinki (right). The collision energies were 20, 30, 40 and 50 eV (left and middle, from top to bottom) and 20, 35 and $50 \mathrm{eV}$ (right). Right panel: in-source CID spectra of haloperidol obtained with an API 365 with orifice-voltage of 20,50 and $80 \mathrm{~V}$, respectively. 


\section{Material, methods and instrumentation}

The following instrumentation was used: two triple-quadrupole mass spectrometers SCIEX API 365 (Freiburg and Helsinki) and one SCIEX API 2000 with a linear accelerator (LINAC) collision cell (in Langen) with turboionspraysource and Multiview 1.4 software. The injection of drug standards was performed by a microliter-syringe pump (infusion at a flow-rate of $20 \mu \mathrm{l} / \mathrm{min}$, drug concentrations of $1 \mu \mathrm{g} / \mathrm{ml}$ were used) or by a HPLC-autosampler. Deionized water, gradient grade acetonitrile, $25 \%$ aqueous ammonia and formic acid (analytical grade) were used for dissolving drug standards in a mixture of solvent A:B (1:1 v/v) (solvent $\mathrm{A}$ : $2 \mathrm{mM}$ ammonium formate $/ 0.1 \%$ formic acid, $\mathrm{pH} 3$; solvent B: acetonitrile $/ 0.1 \%$ formic acid) for positive ionisation. For negative ionisation a drug solution in methanol/water $(1: 1, \mathrm{v} / \mathrm{v})$ was used.

MS/MS-product ion spectra of selected quasimolecular ions, $\mathrm{M}+\mathrm{H}^{+}\left(\right.$or $\left.\mathrm{M}-\mathrm{H}^{-}\right)$were acquired by varying collision energies $(20,30,40,50$ or 20,35 and $50 \mathrm{eV}$, respectively; based on the voltage difference of $\mathrm{Q}_{0}$ and $\mathrm{RO}_{2}$ ) with a collision gas $\left(\mathrm{N}_{2}\right)$ pressure of approximately $2.2 \times 10^{-3}$ Torr.
The third quadrupole $\left(\mathrm{Q}_{3}\right)$ was operated in scan-mode. The library software included in Multiview 1.4 reduces the exact $\mathrm{m} / \mathrm{z}$-values with one decimal to $\mathrm{m} / \mathrm{z}$ values without decimal. For testing the reproducibility (see Tab. II) test compounds $(20 \mathrm{ng})$ were injected onto the LC-system and eluted with a gradient of ammonium acetate $\mathrm{pH} 3.2$ /acetonitrile. Data acquisition was performed by product-ion scan at 20, 35 and $50 \mathrm{eV}$ collision energy.

In-source CID spectra were taken from the "Ion-Spray CID mass spectra library of drugs" (ChemicalSoft, Freiburg/Germany). The acquisition of data for this library had been performed by LC/MS analysis of drug standards (200 ng each) in Q1-scan mode (mass range 50 to $600 \mathrm{amu}$ ) by orifice-voltage switching (20,50 and $80 \mathrm{~V}$, respectively) from one scan to the next.

\section{Results}

In figures 1-3 (left panels) the product ion spectra of the protonated molecules are shown for the test compounds haloperidol $\left(\mathrm{M}+\mathrm{H}^{+}, m / z, 376\right)$, methadone $\left(\mathrm{M}+\mathrm{H}^{+}, m / z, 310\right)$

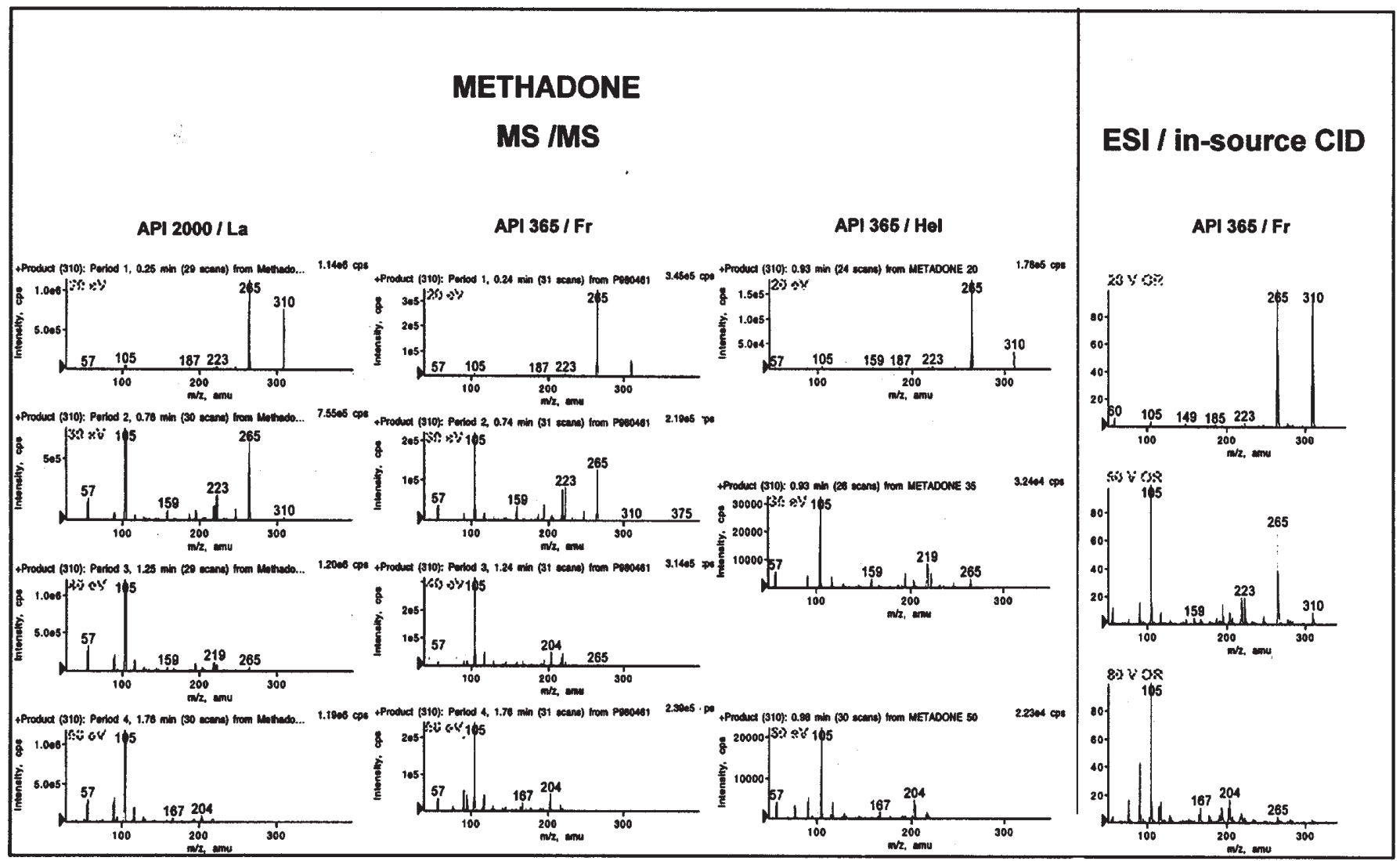

Figure 2. Left panel: MS/MS product ion spectra of methadone $\left(\mathrm{M}_{+} \mathrm{H}^{+}, \mathrm{m} / \mathbf{z} 310\right)$ obtained with an API 2000 in Langen (left), API 365 in Freiburg (middle) and API 365 in Helsinki (right). The collision energies were 20, 30, 40 and $50 \mathrm{eV}$ (left and middle, from top to bottom) and 20, 35 and $50 \mathrm{eV}$ (right). Right panel: in-source CID spectra of methadone obtained with an API 365 with orifice-voltage of 20,50 and $80 \mathrm{~V}$, respectively. 


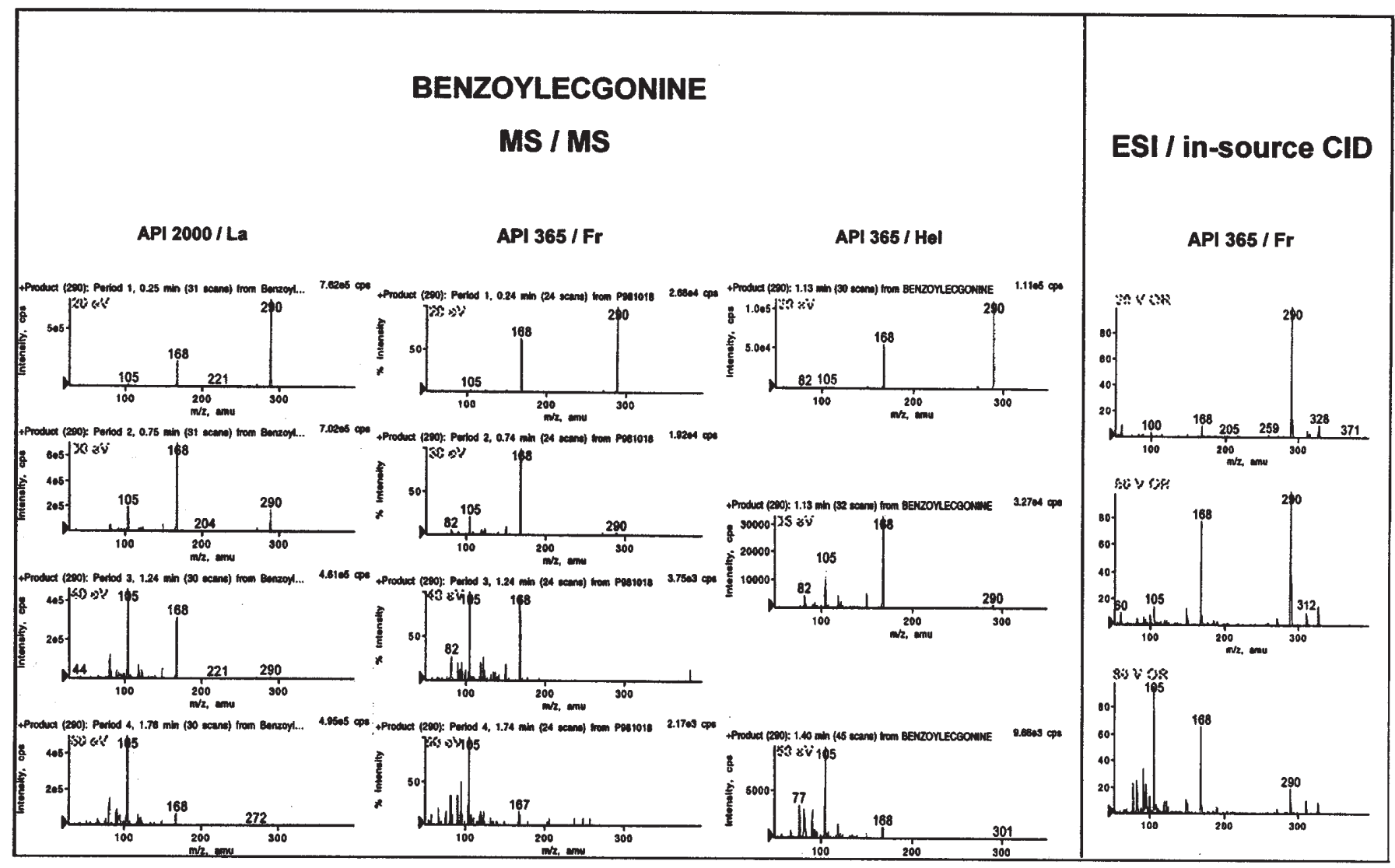

Figure 3. Left panel: MS/MS product ion spectra of benzoylecgonine $\left(\mathrm{M}_{+} \mathrm{H}^{+}, m / z 290\right)$ obtained with an API 2000 in Langen (left), API 365 in Freiburg (middle) and API 365 in Helsinki (right). The collision energies were 20,30,40 and $50 \mathrm{eV}$ (left and middle, from top to bottom) and 20,35 and $50 \mathrm{eV}$ (right). Right panel: in-source CID spectra of benzoylecgonine obtained with an API 365 with orifice-voltage of 20,50 and $80 \mathrm{~V}$, respectively.

and benzoylecgonine $\left(\mathrm{M}+\mathrm{H}^{+}, \mathrm{m} / z, 290\right)$ : the spectra on the left were acquired with an API 2000 in Langen (La), the spectra in the middle with an API 365 in Freiburg (Fr) and the spectra on the right with an API 365 in Helsinki (Hel). The spectra on the left and in the middle ( $\mathrm{Fr}$ and $\mathrm{La}$ ) were acquired with a collision energy of 20, 30, 40 and $50 \mathrm{eV}$ (from top to bottom), respectively; those on the right (Hel) were acquired with 20,35 and $50 \mathrm{eV}$, respectively. In figure 4 the MS/MS spectra (Fr and Hel) of diazepam, acquired with the same conditions as described for figures 1 to 3 are shown.

The comparison of the CID-spectra by MS/MS obtained with these three instruments shows, that the same fragmentions are obtained with only little variations in the ion-ratios between the instruments.

For a direct comparison of product ion spectra, the spectra of haloperidol - obtained with the API 365 in Freiburg and the API 365 in Helsinki, were combined in one library. Each spectrum of haloperidol obtained with one of the three instruments (see Tab. I, first column) was then searched in this combined library. Search results are given in table I. In case of the spectra acquired with the API 365 in Helsinki and in Freiburg, fit values are interesting only for the second, third and fourth hits - not for the first one, because the first hit was the same as the searched spectrum and therefore had a fit of $100 \%$. With an "intensity factor" of 2 in the Multiview software for library searching ambient weight is given to the relative ion-abundances. This was used to get good fit-values for very similar spectra - with respect to similarity of relative ion-abundances - and lower fit values, if a lower or higher degree of fragmentation was observed. Therefore, very good fit values were obtained for spectra, which were acquired at the same collision energy with the APIs 365 and the API 2000. However, it was interesting to see that - although the collision energies differed by $5 \mathrm{eV}$ (30 and $40 \mathrm{eV}$ at $\mathrm{La}$ and at Fr, but $35 \mathrm{eV}$ at $\mathrm{Hel}$ ) - the fit values were still $75 \%$ and $93 \%$ for the second hits (35 eV, Hel) of the $30 \mathrm{eV}$ and $40 \mathrm{eV}$ spectra obtained in Langen with the API 2000. With a lower "intensity factor" even better fit-values (both > $90 \%$ ) would be achievable in these cases.

For testing the reproducibilty of CID-spectra the drugs listed in table II were re-acquired under the same conditions which were used, when the MS/MS library (Hel) was setup. The time period between library set-up and the repeated spectra acquistion was approximately 30 months. The 


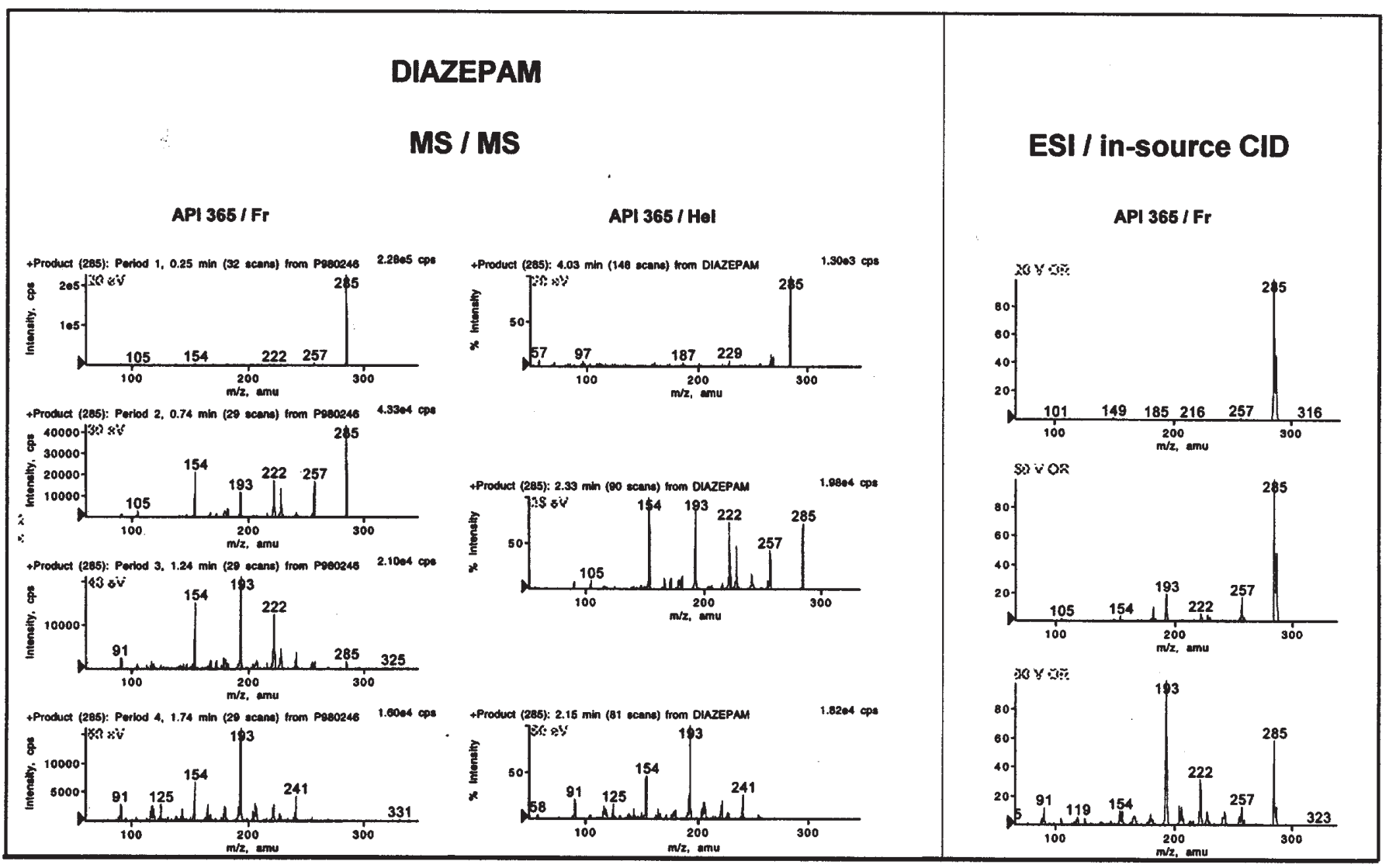

Figure 4. Left panel: MS/MS product ion spectra of diazepam $\left(\mathrm{M}+\mathrm{H}^{+}{ }_{\text {monoisotopic }}, \mathbf{m} / \mathbf{z} 285\right)$ obtained with an API 365 in Freiburg (left) and API 365 in Helsinki (right). The collision energies were 20,30, 40 and $50 \mathrm{eV}$ (left, from top to bottom) and 20, 35 and $50 \mathrm{eV}$ (right). Right panel: in-source CID spectra of diazepam obtained with an API 365 with orifice-voltage of 20, 50 and $80 \mathrm{~V}$, respectively.

resulting library search fit values were between 93 and $99 \%$ (see Tab. II).

The spectra in the right panels of figures 1 to 4 were acquired by in-source CID by different orifice-voltages - a procedure, which has recently been described [1]. As can be seen by comparison of in-source CID spectra (right panels) with MS/MS spectra (left panels), the same fragment-ions are created by both CID-processes due to low energy CID. A main difference is the presence of quasi-molecular ions (with low ion abundance) and fragment ions (with high abundance) in in-source CID spectra with high orifice-voltage (right panel, bottom spectrum), whereas the precursor ions are totally dissociated by MS/MS at high CID energy (left panel, bottom spectra). Furthermore, adduct ions with alkali (see Fig. 3, benzoylecgonine, which contains a carboxylic acid-function) can only be seen with in-source CID, as well as the isotope distribution in case of halogen-containing compounds (see Fig. 4, diazepam). The isotope distribution can not be seen in the MS/MS spectra (Fig. 4, left panel) due to the selection of the monoisotopic protonated molecule as precursor ion.

\section{Conclusions}

Compared to in-source CID, MS/MS in the collision cell of a triple-quadrupole MS has the advantage, that matrix-free mass spectra are obtained, because target analytes are separated from coeluting compounds in the first quadrupole. Therefore, high fit values of library search can be obtained, if the spectra acquisition can be performed in a reproducible way - that this is possible has been demonstrated in this work.

However, the MS/MS method with data dependent experiments has very similar drawbacks as in-source CID/MS, due to the necessity of precursor ion (candidate) selection; these candidates have to be detected in a preliminary LC/MS analysis (survey scan) using single-quadrupole mode before they can be identified or just confirmed by an LC/MS/MS experiment. At this stage the preselection in a survey scan is very critical, due to the possiblity of interferences during the ionisation process (suppression effects) and due to the necessity to use preset thresholds to decide, whether a signal is a candidate or not. With ion-trap detectors, this step might be even more critical, since the total number of ions allowed to enter an ion-trap is usually restricted, which is a 
Table I. Library search results for haloperidol (see figure 1) with a combination of the libraries of Freiburg (API 365) and Helsinki (API 365).

\begin{tabular}{|c|c|c|c|c|}
\hline $\begin{array}{l}\text { Haloperidol } \\
\text { spectrum searched }\end{array}$ & $\begin{array}{l}1 s t \text { Hit } \\
\text { Fit - \% }\end{array}$ & $\begin{array}{l}\text { 2nd Hit } \\
\text { Fit - \% }\end{array}$ & $\begin{array}{l}\text { 3rd Hit } \\
\text { Fit - \% }\end{array}$ & $\begin{array}{l}\text { 4th Hit } \\
\text { Fit - } \%\end{array}$ \\
\hline $20 \mathrm{eV} \mathrm{Fr}$ & $\begin{array}{c}20 \mathrm{eV} \mathrm{Fr} \\
100^{\mathrm{a}}\end{array}$ & $\begin{array}{c}20 \mathrm{eV} \mathrm{Hel} \\
99\end{array}$ & $\begin{array}{l}30 \mathrm{eV} F r \\
44\end{array}$ & $\begin{array}{c}50 \mathrm{eV} \mathrm{Hel} \\
39\end{array}$ \\
\hline $30 \mathrm{eV} \mathrm{Fr}$ & $\begin{array}{c}30 \mathrm{eV} \mathrm{Fr} \\
100^{\mathrm{a}}\end{array}$ & $\begin{array}{c}35 \mathrm{eV} \mathrm{Hel} \\
93\end{array}$ & $\begin{array}{l}40 \mathrm{eV} \mathrm{Fr} \\
69\end{array}$ & $\begin{array}{c}50 \mathrm{eV} \mathrm{Hel} \\
55\end{array}$ \\
\hline $40 \mathrm{eV} \mathrm{Fr}$ & $\begin{array}{c}40 \mathrm{eV} \mathrm{Fr} \\
100^{\mathrm{a}}\end{array}$ & $\begin{array}{c}50 \mathrm{eV} \mathrm{Hel} \\
94\end{array}$ & $\begin{array}{c}35 \mathrm{eV} \mathrm{Hel} \\
90\end{array}$ & $\begin{array}{c}50 \mathrm{eV} \mathrm{Fr} \\
82\end{array}$ \\
\hline $50 \mathrm{eV} \mathrm{Fr}$ & $\begin{array}{c}50 \mathrm{eV} \mathrm{Fr} \\
100^{\mathrm{a}}\end{array}$ & $\begin{array}{c}50 \mathrm{eV} \mathrm{Hel} \\
96\end{array}$ & $\begin{array}{l}40 \mathrm{eV} \mathrm{Fr} \\
89\end{array}$ & $\begin{array}{c}35 \mathrm{eV} \mathrm{Hel} \\
54\end{array}$ \\
\hline $20 \mathrm{eV} \mathrm{Hel}$ & $\begin{array}{c}20 \mathrm{eV} \mathrm{Hel} \\
100^{\mathrm{a}}\end{array}$ & $\begin{array}{l}20 \mathrm{eV} \mathrm{Fr} \\
99\end{array}$ & $\begin{array}{l}30 \mathrm{eV} \mathrm{Fr} \\
43\end{array}$ & $\begin{array}{c}50 \mathrm{eV} \mathrm{Hel} \\
40\end{array}$ \\
\hline $35 \mathrm{eV} \mathrm{Hel}$ & $\begin{array}{c}35 \mathrm{eV} \mathrm{Hel} \\
100^{\mathrm{a}}\end{array}$ & $\begin{array}{l}30 \mathrm{eV} \mathrm{Fr} \\
92\end{array}$ & $\begin{array}{l}40 \mathrm{eV} \mathrm{Fr} \\
89\end{array}$ & $\begin{array}{c}50 \mathrm{eV} \mathrm{Hel} \\
68\end{array}$ \\
\hline $50 \mathrm{eV} \mathrm{Hel}$ & $\begin{array}{c}50 \mathrm{eV} \mathrm{Hel} \\
100^{\mathrm{a}}\end{array}$ & $\begin{array}{c}40 \mathrm{eV} \mathrm{Fr} \\
93\end{array}$ & $\begin{array}{l}50 \mathrm{eV} \mathrm{Fr} \\
90\end{array}$ & $\begin{array}{c}35 \mathrm{eV} \mathrm{Hel} \\
61\end{array}$ \\
\hline $20 \mathrm{eV}$ La/API 2000 & $\begin{array}{l}20 \mathrm{eV} \mathrm{Fr} \\
99\end{array}$ & $\begin{array}{c}20 \mathrm{eV} \mathrm{Hel} \\
99\end{array}$ & $\begin{array}{c}50 \mathrm{eV} \mathrm{Hel} \\
55\end{array}$ & $\begin{array}{c}35 \mathrm{eV} \mathrm{Hel} \\
41\end{array}$ \\
\hline $30 \mathrm{eV}$ La/API 2000 & $\begin{array}{l}30 \mathrm{eV} \mathrm{Fr} \\
92\end{array}$ & $\begin{array}{c}35 \mathrm{eV} \mathrm{Hel} \\
75\end{array}$ & $\begin{array}{c}50 \mathrm{eV} \mathrm{Hel} \\
85\end{array}$ & $\begin{array}{c}30 \mathrm{eV} \mathrm{Fr} \\
81\end{array}$ \\
\hline $40 \mathrm{eV}$ La/API 2000 & $\begin{array}{c}40 \mathrm{eV} \mathrm{Fr} \\
94\end{array}$ & $\begin{array}{c}35 \mathrm{eV} \mathrm{Hel} \\
93\end{array}$ & $\begin{array}{c}50 \mathrm{eV} \mathrm{Hel} \\
85\end{array}$ & $\begin{array}{c}30 \mathrm{eV} F r \\
81\end{array}$ \\
\hline $50 \mathrm{eV}$ La/API 2000 & $\begin{array}{c}50 \mathrm{eV} \mathrm{Hel} \\
98\end{array}$ & $\begin{array}{c}50 \mathrm{eV} \mathrm{Fr} \\
95\end{array}$ & $\begin{array}{c}40 \mathrm{eV} \mathrm{Fr} \\
90\end{array}$ & $\begin{array}{c}35 \mathrm{eV} \mathrm{Hel} \\
70\end{array}$ \\
\hline
\end{tabular}

a $100 \%$ fit: library spectrum and spectrum searched were identical.

Table II. Reproducibility of MSMS spectra with API 365 (Hel).

\begin{tabular}{lccccc}
\hline Compound & $\mathrm{M}+\mathrm{H}^{+}$ & $\mathrm{CE}, \mathrm{eV}$ & \multicolumn{2}{c}{ Acquired spectrum } & Library spec. \\
\cline { 3 - 5 } & & & Fit $-\%$ & Date & Date \\
\hline Venlafaxine & 278 & 20 & 93 & 1.11 .00 & 11.05 .98 \\
Oxazepam & 287 & 20 & 95 & 1.11 .00 & 30.05 .98 \\
Aminophenazone & 232 & 20 & 94 & 1.11 .00 & 11.05 .98 \\
Olanzapine & 313 & 35 & 94 & 1.11 .00 & 05.05 .98 \\
Triazolam & 343 & 35 & 93 & 1.11 .00 & 17.04 .98 \\
Amitriptyline & 278 & 35 & 93 & 1.11 .00 & 17.05 .98 \\
Doxepin & 280 & 50 & 94 & 1.11 .00 & 18.05 .98 \\
Carbamazepine & 237 & 50 & 99 & 1.11 .00 & 24.03 .98 \\
Clozapine & 301 & 50 & 95 & 1.11 .00 & 21.04 .98 \\
\hline
\end{tabular}


handicap when trace amounts of analyte are to be detected in presence of coeluting substances or background ions. However, the comparsion of triple-quadrupole and ion-trap MS/MS analysis was not aim of this study.

The main perspective of MS/MS libraries might be the screening for selected compounds as shown in the applications below. Furthermore, with internal (deuterated) standards, a quantitation of selected compounds by MS/MS is possible in one LC-run - similar to a method published for selected drugs in serum by flow-injection MS/MS-analysis [5]. The identification of metabolites by the similarity of the CID-spectra of metabolites and parent drugs is another possible application of a MS/MS-spectra library, and has recently been demonstrated by the identification of oxidised sildenafil and two more sildenafil metabolites in urine [19].

MS/MS library searching in combination with data dependent experiments in two separate LC-analyses with the use of macros has been successfully applied in the two following examples in the field of forensic toxicology.

\section{Application 1}

A screening method for 16 selected $\beta$-blocking drugs has been developed for the analysis of urine samples from autopsy [10]. MS/MS library searching has been used as an automatic confirmation step in this procedure. Samples were first pre-screened for the presence of any $\beta$-blocking drugs using LC/MS with selected ion monitoring (SIM). In this step the identification was based on their liquid chromatographic retention times and their protonated molecules. If any beta-blocking drugs were found to be present, an automatic confirmation step by LC-MS/MS product ion spectra was followed. This step was a data depended experiment, which involved the acquisition of a product ion spectrum of the detected protonated molecules and searching them against an MS/MS product ion library of 400 therapeutic and illegal drugs (MS/MS library of Helsinki). The reported screening and confirmation method was automated by using a macro program (Auto MS/MS Builder, Sciex). In the described macro, the user defined a list of names, expected retention times and masses of the protonated molecules to be screened. The retention time window and minimum peak intensity were also user definable. The LC/MS/SIM screening method and the state file settings for acquiring the LC/MS/MS product ion spectra were set before starting the sample batch. The collision energy was the same that had been used for building the MS/MS library (35 eV). In routine work, the user only had to write a sample batch and start the macro. After the screening run of every sample, the program automatically searched for hits and - based on the number of hits and on the respective protonated molecules - created an individual LC/MS/MS product ion method for every sample. The macro started the confirmation run and searched the obtained product ion spectra against the MS/MS library and finally reported the results in an Excel sheet. Then the macro automatically started to screen the next sample. During the library search procedure, the crite- ria for confirmation of the identification was spectral match of 70 percentage (Fit \%). The limits of identification in the MS/MS product ion scan ranged from $0.02 \mathrm{mg} / \mathrm{L}$ (carvedilol) to $1.2 \mathrm{mg} / \mathrm{L}$ (pindolol), the majority of the values being below $0.2 \mathrm{mg} / \mathrm{L}$.

\section{Application 2}

In another forensic application, 18 antihistamine drugs were screened, confirmed and quantitated in autopsy blood samples using the same macro (Auto MS/MS Builder for automatic DDE and library search) as in the application 1 [20]. In this study, screening was performed with multiple reaction monitoring (MRM) because the data were also used for quantitation of very low concentrations of antihistamines. The primary intention of the authors had been to monitor several fragment ions simultaneously by MRM for confirmation purposes, but this approach could not be applied, because it resulted in a remarkable loss of sensitivity since higher collision energies had to be used to obtain more than one fragment ion. Therefore, the confirmation was performed with a separate LC/MRM-analysis. The collision energies for the LC/MRM screening step were optimized for all drugs separately to achieve one fragment ion as intensive as possible. However, during the confirmation step the macro allowed only one collision energy (state file) to be chosen for acquiring the product ion spectra. The state file with collision energy of $35 \mathrm{eV}$ was chosen because it was used when acquiring the MS/MS library spectra. As a result, the validated quantitation limits by MRM were lower than the limits for verification by product ion spectra when library matches better than $70 \%$ were required. However, therapeutic levels of antihistamines could be verified by this procedure.

\section{Acknowledgments}

We would like to thank Dr. Michal Svoboda and André Schreiber for the acquisition of MS/MS spectra with the API 2000 in the LC/MS Application Laboratory of Applied Biosystems in Langen/Germany.

\section{References}

1. Weinmann, W.; Wiedemann, A.; Eppinger, B.; Renz, M.; Svoboda, M. J. Am. Soc. Mass Spectrom. 1999, 10 1028-1037.

2. Schreiber, A.; Efer, J.; Engewald, W. GIT Spezial, 1999, 1, 1012.

3. Schreiber A., Efer, J.; Engewald, W. J. Chromatogr. A 2000 , 869, 411-425.

4. Marquet, P.; Lachâtre, G. J. Chromatogr. B 1999, 733, 93-118.

5. Weinmann, W.; Svoboda, M. J. Anal. Toxicol. 1998, 22, 319328.

6. Mueller, C.; Vogt, S.; Goerke, R.; Kordon, A.; Weinmann, W. For. Sci. Int. 2000, 113, 415-421.

7. Weinmann, W.; Vogt, S.; Goerke, R.; Mueller, C.; Bromberger, A. For. Sci. Int. 2000, 113, 381-387. 
8. Marquet, P.; Venisse, N.; Lacassie, E.; Lachâtre, G. Analusis this issue.

9. Weinmann, W.; Lehmann, N.; Müller, C.; Wiedemann, A.; Svoboda, M. For. Sci. Int. 2000, 113, 339-344.

10. Gergov, M.; Robson, J.N.; Duchoslav, E.; Ojanperä, I. J. Mass Spectrom. 2000, 35, 912-918.

11. Sander, P. Substance identification of ion-trap MS/MS spectra in a MS/MS library; poster, $47^{\text {th }}$ Conf Am Soc Mass Spectrom Allied Topics, Dallas, 1999.

12. Rittner, M.; Jastorff, P.; Stacey, C.; Sander, P.; Ingendoh, A. A new approach in LC/MS library search using combined MS and MSn ESI ion trap spectra. Poster, $48^{\text {th }}$ Conf Am Soc Mass Spectrom Allied Topics, Long Beach, 2000.

13. Eichler, M.; Cintora, M.A.; Lifante, E.; Cooke, M.; Przyborowska, A.; Down, S.; Patel, R.K.P.; Halket, J.M. LC/MS/MS library searching for rapid confirmation of analytes in clinical, environmental and food chemistry. Poster, $48^{\text {th }}$ Conf Am Soc Mass Spectrom Allied Topics, Long Beach, 2000.

14. Baumann, C.; Cintora, M.A.; Eichler, M.; Lifante, E.; Cooke, M. Przyborowska, A.; Halket, J.M. Rapid Commun. in Mass Spectrom. 2000, 14, 349-56.
15. Yang, M.; Bonner, R.; Burton, L.; Bloomfield, N.; Le Blanc, J.C.Y. Application of New Data Dependent Experiments. Poster, $48^{\text {th }}$ Conf Am Soc Mass Spectrom Allied Topics, Long Beach, 2000.

16. Monasterios, C.J.; Duchoslav, E.; Chervetsova, I.; Pekar, D.; Yang, M.; Mouget, Y.; Sojo, L.E.; Howie, H. Detection and characterization of modern pesticides, their metabolites and degradation products by LC/MS/MS. Poster, $48^{\text {th }}$ Conf Am Soc Mass Spectrom Allied Topics, Long Beach, 2000.

17. Kovarik, P.; Mouget, Y.; Sakuma, T. HPLC/MS/MS analysis of bitter acids in hops and beer. Poster, $48^{\text {th }}$ Conf Am Soc Mass Spectrom Allied Topics, Long Beach, 2000.

18. Yates, J.R.; Morgan, S.F.; Gatlin, C.L.; Griffin, P.R. Anal. Chem. 1998, 70, 3557-3565.

19. Weinmann, W.; Bohnert, M.; Wiedemann, A.; Renz, M.; Lehmann, N.; Pollak, S. Int. J. Legal Med. 2000, in press.

20. Gergov, M.; Robson, J.N.; Vuori, E. For. Sci. Int. 2000, submitted for publication. 